\title{
Prevalence and Factors Associated with High-Risk Pregnancies in Lubumbashi, Democratic Republic of Congo
}

\author{
Yayila Tshimba Sylvie1, Khaki Khang Mariette1, Kiluba Tshikala Pichou1, \\ Tendilonge Kasilembo Jean de Dieuㅁ, Ilunga Kakahi Blaise², Kabamba Nzaji Michel ${ }^{3}$ \\ ${ }^{1}$ Nursing Science, Higher Institute of Medical Techniques of Lubumbashi, Lubumbashi, Democratic Republic of Congo \\ ${ }^{2}$ Higher Institute of Medical Techniques of Lubumbashi, Lubumbashi, Democratic Republic of Congo \\ ${ }^{3}$ Department of Public Health, Faculty of Medicine, University of Kamina, Kamina, Democratic Republic of Congo \\ Email: michelnzaji@yahoo.fr
}

How to cite this paper: Sylvie, Y.T., Mariette, K.K., Pichou, K.T., de Dieu, T.K.J., Blaise, I.K. and Michel, K.N. (2017) Prevalence and Factors Associated with High-Risk Pregnancies in Lubumbashi, Democratic Republic of Congo. Open Access Library Journal, 4: e4162. https://doi.org/10.4236/oalib.1104162

Received: November 16, 2017 Accepted: December 12, 2017 Published: December 15, 2017

Copyright $\odot 2017$ by authors and Open Access Library Inc.

This work is licensed under the Creative Commons Attribution International License (CC BY 4.0).

http://creativecommons.org/licenses/by/4.0/

\begin{abstract}
Introduction: Pregnancy is a special natural and physiological event that is not always normally and is responsible for morbidity and preventable mortality. Pregnancy risk is defined as one that is complicated by a factor or factors that negatively affect the outcome of pregnancy the mother's side and/or perinatal. This study was assigned as targets to determine the risk pregnancy prevalence and the factors associated with these pregnancies. Materiel and Method: We conducted a cross-sectional descriptive study at the General Hospital Katuba in Lubumbashi for a period of three months from March to June 2017. Result: Our results showed that $11.5 \%$ of pregnancies were high risk and moderate in $21.6 \%$. Overall, pregnancies were high or moderate risk of $33.1 \%$. A proportion of $19.8 \%$ of new mothers were aged over 35 years and $3.4 \%$ were under 18 years. The average age was $28.8 \pm 7.2$ years. Age greater than 35 years, multiparity, the high parity, the multigestity and the large multigestity were significantly associated with a risk pregnancy OR: 181 [43.08 to 762.99], OR 16.04 [6, from 44 to 40.00] OR: 232.39 [58.60 to 971.36] OR: 5.15 [2.06 to 12.87] OR: 78.67 [25.77 to 240,15 . diabetes history OR $=6.32$ [1.26 to 31.78], perinatal mortality $(\mathrm{p}=0.006)$ and repeated abortions $(\mathrm{p}=0.023)$ were also significantly related to a pregnancy at risk. Conclusion: A good support suitable or adequate based on risk could never be achieved without close collaboration between stakeholders and health professionals perinatal and follow the microscope stage of the support organization.
\end{abstract}

\section{Subject Areas}

Gynecology \& Obstetrics 


\section{Keywords}

Prevalence, Risk Pregnancy, Associated Factors, Lubumbashi

\section{Introduction}

Pregnancy is a special natural and physiological event that is not always normally and is responsible for morbidity and preventable mortality. Pregnancy risk is defined as one that is complicated by a factor or factors that negatively affect the outcome of pregnancy the mother's side and/or perinatal [1]. Among mothers seen prenatally, only $10 \%$ to $30 \%$ of mothers are classified as high risk. Among these mothers, $70 \%$ to $80 \%$ are left with mortality or perinatal morbidity [2].

A high-risk pregnancy refers to anything that puts the mother, the fetus or newborn at increased risk of morbidity and mortality during pregnancy and childbirth. According to the study Samar K. Hafez, $44 \%$ of Saudi women with a high risk pregnancy had an age between 30 and 35 years, $60 \%$ of them were obese, $62 \%$ had between 5 gestity - 12 previous pregnancies, about half of them (47\%) had a parity between 5 and $11,35 \%$ had a history of more than 2 abortions. About two-thirds (66\%) of them had complicated pregnancies in the past and $68.7 \%$ of them complained of conditions such as anemia (25.3\%), gestational diabetes (16.2 \%), hypertension (15.2\%) [3]. By against study Sapna Jain found that of 415 women, 96 (59\%) were at high risk, 191 (46\%) were low risk and 128 (31\%) had no risk. In the high-risk group, there were 59 perinatal deaths and perinatal mortality rate was very high (614 per 1000 live births) [4].

A high-risk pregnancy is one in which the life or health of the mother or fetus are compromised or threatened by a conjugate or disorder unique to pregnancy. Risk factors may be pre-existing factors before or during the prenatal visit or can develop later in the current pregnancy. Nearly $50 \%$ of all maternal complications and $60 \%$ of primary cesarean come from a high-risk group [5].

Thus, our study was assigned as targets to determine the prevalence of high risk pregnancy and the factors associated with the occurrence of a risk pregnancy in women in the city of Lubumbashi.

\section{Material and Method}

\subsection{Study Type}

This study is descriptive cross prevalence and factors underlying risk pregnancies in the city of Lubumbashi.

\subsection{Study Population}

The target population for this study consisted of all women admitted and treated in the Gynecology and Obstetrics Service of the General Hospital of Katuba Reference for a period of three months from March to June 2017. To be included in this study, the following conditions should be met in women who delivered in 
the selected structure for our study and a complete medical file. Pregnant women do not meet all the criteria listed above have not been retained.

\subsection{Sample Size and Sampling}

Our sample is comprehensive. We selected all women in labor who attended the Gynecology obstetric service structures mentioned above. The sample was made up of all pregnancy collected during the study period 384 women in labor.

\subsection{Management and Data Collection}

The different information about patients or pregnant women were collected on individual holdings records or survey forms previously established and used as data carrier.

\subsection{Statistical Analysis}

The collected information was entered with Excel 2015 Office and were analyzed using the software Statistical Package for Social Science (SPSS) Version 23. Regarding the statistical test, we used the p-value of the chi square test of Pearson and Fisher exact. A statistically significant difference was accepted if $p$ is less than or equal to 0.05 . The evaluation of risk factors was made based on the following parameters: risks related to land (Age less than 18 or greater than 35 years, Height: less than $152 \mathrm{~cm}$ ); Risk general history (hypertension, diabetes), risk obstetrical history (Recurrent miscarriages, premature deliveries, uterine malformation known, confinement of dysmature and perinatal deaths); risks related to pathology confirmed pregnancy (Twin pregnancy, hemorrhages of the 2nd and 3rd quarters). The values of all high-risk factors were added and a total score determined whether the pregnancy was "no risk" to "medium risk" or "high risk" as a result and have been classified as: No risk with score $0-3$, medium Risk with the score $4-9$, with the high risk score of 10 or $>10$.

\subsection{Ethical Considerations}

While it is true that any study to be conducted on human beings requires respect for human right. Our study has been spared. All pregnant women had received information about the research object. We are reassured that the good understanding and we asked their consent after the free and informed choice when all mental faculties are in place. All pregnant women were treated fairly. We reassured them of anonymity and confidentiality of information.

\section{Results}

It appears from this Table 1 that $19.8 \%$ of new mothers were aged over 35 years and $3.4 \%$ were under 18 years. The average age was $28.8 \pm 7.2$ years. Thirteen percent of new mothers were high parity and $24.7 \%$ were primiparous. The average parity was $3.3 \pm 2.7$; Seventy-two birth $(18.8 \%)$ were major multigravidae and $65(16.9 \%)$ were primigravida. In connection with the level of education 22 , 
Table 1. Characteristics of women surveyed.

\begin{tabular}{|c|c|c|}
\hline Age & Effective $(n=384)$ & Percentage \\
\hline$<18$ & 13 & $3.4 \%$ \\
\hline $18-35$ & 295 & $76.8 \%$ \\
\hline$>35$ years & 76 & $19.8 \%$ \\
\hline \multicolumn{3}{|l|}{ Parity } \\
\hline nulliparous & 17 & $4.4 \%$ \\
\hline primipare & 95 & $24.7 \%$ \\
\hline few previous deliveries & 120 & $31.3 \%$ \\
\hline multiparous & 102 & $26.6 \%$ \\
\hline great multipare & 50 & $13.0 \%$ \\
\hline \multicolumn{3}{|l|}{ gravidity } \\
\hline gravida & 65 & $16.9 \%$ \\
\hline Paucigeste & 119 & $31.0 \%$ \\
\hline multigravida & 128 & $33.3 \%$ \\
\hline great multigravida & 72 & $18.8 \%$ \\
\hline \multicolumn{3}{|l|}{ Educational level } \\
\hline No & 88 & $22.92 \%$ \\
\hline Primary & 28 & $7.29 \%$ \\
\hline Secondary & 167 & $43.49 \%$ \\
\hline University & 101 & $26.30 \%$ \\
\hline \multicolumn{3}{|l|}{ Marital status } \\
\hline living alone & 27 & $7.03 \%$ \\
\hline Common-law & 357 & $92.97 \%$ \\
\hline
\end{tabular}

$92 \%$ of new mothers were illiterate and $7.29 \%$ had a primary level and $7.03 \%$ of new mothers living alone (single, widowed) and $92.97 \%$ were in union.

It should be noted that the prevalence of high-risk pregnancy was high in $11.5 \%$ of cases, moderate in $21.6 \%$. Overall, pregnancies were high or moderate risk of $33.1 \%$ (Table 2).

It appears from this Table 3 that age over 35 years, multiparity, the high parity, the multigestity and the large multigestity were significantly associated with a risk pregnancy OR: 181 [43.08 - 762.99], OR : 16.04 [6.44 - 40.00] OR: 232.39 [58.60 - 971.36] OR: 5.15 [2.06 - 12.87] OR: 78.67 [ 25.77 - 240.15].

It is apparent from this Table 4 that the history of diabetes $(\mathrm{OR}=6.32[1.26$ $31.78])$, perinatal mortality $(p=0.006)$ and repeated abortions $(p=0.023)$ were significantly associated with pregnancy risk.

It is apparent from this Table 5 that hypertension $(\mathrm{OR}=17.21[2.13-$ 139.18]), the third-trimester bleeding $(\mathrm{OR}=8.57[1.79-40.98])$ and diabetes $(\mathrm{p}$ $=0.013$ ) were significantly associated with a risk pregnancy. 
Table 2. Risk pregnancy prevalence in women surveyed.

\begin{tabular}{ccc}
\hline Type of risk & Effective & Percentage \\
\hline No & 257 & $66.9 \%$ \\
Moderate & 83 & $21.6 \%$ \\
High & 44 & $11.5 \%$ \\
Total & 384 & $100 \%$ \\
\hline
\end{tabular}

Table 3. Association between the characteristics of women and prevalence of high-risk pregnancy.

\begin{tabular}{|c|c|c|c|c|}
\hline \multirow{2}{*}{ Women Features } & \multicolumn{2}{|c|}{ Status of pregnancy } & \multirow{2}{*}{$\begin{array}{c}\text { OR } \\
{[95 \% \mathrm{CI}]}\end{array}$} & \multirow[b]{2}{*}{$\mathrm{p}$} \\
\hline & $\begin{array}{l}\text { moderate or } \\
\text { high risk }\end{array}$ & No risk & & \\
\hline \multicolumn{5}{|l|}{ Age of woman } \\
\hline$<18$ & $3(23.1 \%)$ & $10(76.9 \%)$ & $1.47[0.39-5.53]$ & 0.57 \\
\hline $18-35$ & $50(16.9 \%)$ & $245(83.1 \%)$ & & \\
\hline 35 years & $74(97.4 \%)$ & $2(2.6 \%)$ & 181 [43.08 - 762.99] & $<0.0001$ \\
\hline \multicolumn{5}{|l|}{ Civil status } \\
\hline Married life & $118(33.1 \%)$ & $239(66.9 \%)$ & $0.99[0.43-2.26]$ & 0.98 \\
\hline only life & $9(33.3 \%)$ & $18(66.7 \%)$ & & \\
\hline \multicolumn{5}{|l|}{ Parity } \\
\hline nulliparous & $5(29.4 \%)$ & $12(70.6 \%)$ & $6.18[1.63-23.35]$ & 0,003 \\
\hline primipare & $6(6.3 \%)$ & $89(93.7 \%)$ & & \\
\hline $\begin{array}{c}\text { few previous delive- } \\
\text { ries }\end{array}$ & $16(13.3 \%)$ & $104(86.7 \%)$ & $2.28[0.86-6.08]$ & 0.091 \\
\hline multipare & $53(52.0 \%)$ & $49(48.0 \%)$ & $16.04[6.44-40.00]$ & $<0.0001$ \\
\hline great multipare & $47(94.0 \%)$ & $3(6.0 \%)$ & $232.39[58.60-971.36]$ & $<0.0001$ \\
\hline \multicolumn{5}{|l|}{ gravidity } \\
\hline gravida & $6(9.2 \%)$ & $59(90.8 \%)$ & & \\
\hline paucigeste & $13(10.9 \%)$ & $106(89.1 \%)$ & $1.21[0.44-3.34]$ & 0.72 \\
\hline multigravida & $44(34.4 \%)$ & $84(65.6 \%)$ & $5.15[2.06-12.87]$ & $<0.0001$ \\
\hline great multigravida & $64(88.9 \%)$ & $8(11.1 \%)$ & $78.67[25.77-240.15]$ & $<0.0001$ \\
\hline \multicolumn{5}{|l|}{$\begin{array}{l}\text { Size of the mother } \\
\text { in meter }\end{array}$} \\
\hline$<1.50$ & $2(18.2 \%)$ & $9(81.8 \%)$ & $0.44[0.09-2.07]$ & 0.29 \\
\hline$\geq 1.50$ & $125(33.5 \%)$ & $248(66.5 \%)$ & & \\
\hline
\end{tabular}

\section{Discussion}

Pregnancy is considered a physiological and unique period in the lives of women. However, an unpredictable disease of the mother or fetus can complicate pregnancy. Pregnancy is defined as "high risk" if the possibility of an adverse outcome is higher. 
Table 4. Association between the woman's history and prevalence of high-risk pregnancy.

\begin{tabular}{|c|c|c|c|c|}
\hline \multirow[b]{2}{*}{ History of women } & \multicolumn{2}{|c|}{ Status of pregnancy } & \multirow[b]{2}{*}{ OR $[95 \% \mathrm{CI}]$} & \multirow[b]{2}{*}{$\mathrm{p}$} \\
\hline & $\begin{array}{c}\text { moderate or } \\
\text { high risk }\end{array}$ & No risk & & \\
\hline \multicolumn{5}{|l|}{ Diabetes } \\
\hline Yes & $6(75.0 \%)$ & $2(25.0 \%)$ & $6.32[1.26-31.78]$ & 0,030 \\
\hline No & $121(32.2 \%)$ & $255(67.8 \%)$ & & \\
\hline \multicolumn{5}{|l|}{ hypertension } \\
\hline Yes & $2(66.7 \%)$ & $1(33.3 \%)$ & $4.10[0.37-45.61]$ & 0.53 \\
\hline No & $125(32.8 \%)$ & $256(67.2 \%)$ & & \\
\hline \multicolumn{5}{|l|}{ macrosomia } \\
\hline Yes & $2(40.0 \%)$ & $3(60.0 \%)$ & $1.35[0.22-8.21]$ & 0.88 \\
\hline No & $125(33.0 \%)$ & $254(67.0 \%)$ & & \\
\hline \multicolumn{5}{|l|}{ perinatal mortality } \\
\hline Yes & $5(100.0 \%)$ & $0(0.0 \%)$ & & 0.006 \\
\hline No & $122(32.2 \%)$ & $257(67.8 \%)$ & & \\
\hline \multicolumn{5}{|l|}{ Habitual abortion } \\
\hline Yes & $4(100.0 \%)$ & $0(0.0 \%)$ & & 0,023 \\
\hline No & $123(32.4 \%)$ & $247(67.6 \%)$ & & \\
\hline
\end{tabular}

Table 5. Association of pathologies during pregnancy and prevalence of high-risk pregnancy.

\begin{tabular}{|c|c|c|c|c|}
\hline \multirow[b]{2}{*}{ Pathology during pregnancy } & \multicolumn{2}{|c|}{ Status of pregnancy } & \multirow{2}{*}{$\begin{array}{c}\text { OR } \\
{[95 \% \mathrm{CI}]}\end{array}$} & \multirow[b]{2}{*}{$\mathrm{p}$} \\
\hline & $\begin{array}{c}\text { moderate } \\
\text { or high risk }\end{array}$ & No risk & & \\
\hline \multicolumn{5}{|l|}{ hypertension } \\
\hline Yes & $8(88.9 \%)$ & $1(11.1 \%)$ & $17.21[2.13-139.18]$ & 0,001 \\
\hline No & $119(31.7 \%)$ & $256(68.3 \%)$ & & \\
\hline \multicolumn{5}{|l|}{ Diabetes } \\
\hline Yes & $3(100.0 \%)$ & $0(0.0 \%)$ & & 0,013 \\
\hline No & $124(32.5 \%)$ & $257(67.5 \%)$ & & \\
\hline \multicolumn{5}{|l|}{ Bleeding in the third quarter } \\
\hline Yes & $8(80.0 \%)$ & $2(20.0 \%)$ & $8.57[1.79-40.98]$ & 0,003 \\
\hline No & $119(31.8 \%)$ & $255(68.2 \%)$ & & \\
\hline \multicolumn{5}{|l|}{$\begin{array}{c}\text { premature rupture of } \\
\text { membranes }\end{array}$} \\
\hline Yes & $4(66.7 \%)$ & $2(33.3 \%)$ & $4.15[0.75-22.95]$ & 0.096 \\
\hline No & $123(32.5 \%)$ & $255(67.5 \%)$ & & \\
\hline \multicolumn{5}{|l|}{ urinary infection } \\
\hline Yes & $9(29.0 \%)$ & $22(71.0 \%)$ & $0.81[0.36-1.82]$ & 0.618 \\
\hline No & $118(33.4 \%)$ & $235(66.6 \%)$ & & \\
\hline
\end{tabular}


Our study showed that $11.5 \%$ of mothers had a high risk, $21.6 \%$ moderate risk and $66.9 \%$ low risk. Overall, pregnancies in high or moderate risk were of the order of 33.1\%. Simarpreet, Mamta, Pooja et al., In 2015, had been found that over a third of $35 \%$ of pregnant women were at low risk, a third of women $33 \%$ had a moderate risk, $30 \%$ had a high risk and only $2 \%$ had very high risk factors [6]. Results largely higher to ours as the studies conducted by Samar K. Hafez [3] were reported a prevalence of $63.3 \%$ of high-risk pregnancy while those Yassein et al. [7] found a prevalence of $63.8 \%$. Bharti et al. also revealed a prevalence of high-risk pregnancy of $31.4 \%$ [8]. Note that this rate is actually so low compared to other studies, such as those Jain et al. Which are a proportion of $41.5 \%$ in Nepal and Al Teheawy with a rate of $46.2 \%$ in Saudi Arabia in 1992, 21\% in Cameroon between 1982 and 1985. And that observed in Belgium, 21.8\% in 2005. This difference may be due to the use of different tools to measure a high-risk pregnancy [9].

Multiparity the high parity, the multigestity and the large multigestity were significantly associated with a risk pregnancy OR: 181 [43.08 - 762.99], OR 16.04 [6.44 - 40.00] OR: 232.39 [58.60 - 971.36] OR: 5.15 [2.06 - 12.87] OR: 78.67 [25.77 - 240.15]. Support for this result was observed in a study in Erbil in 2012, which showed that there was a significant association between age and number of pregnancies (gravidity $>5$ ). [10]

Our study found a statistically significant association between hypertension $(\mathrm{OR}=17.21[2.13-139.18])$, Diabetes $(\mathrm{p}=0.013)$, the third-trimester bleeding $(\mathrm{OR}=8.57[1.79-40.98])$ and pregnancy in high or medium risk Note that preeclampsia, disorder hypertensive pregnancy is estimated to complicate $2 \%$ to $8 \%$ of pregnancies and is the leading cause of morbidity and maternal and fetal mortality. Pre-eclampsia may be present at any gestation but is more commonly found in the third quarter. Several risk factors have been documented, including: family history, Nulliparity, diabetes and obesity. High blood pressure (hypertension) during pregnancy is a major cause of morbidity and fetal mortality, neonatal but maternal.

For Akhtar, preeclampsia, pregnancy-induced hypertension and gestational diabetes were the main risk factors [11]. Note that when a woman has a problem during pregnancy, such as premature birth, birth defects, history of abortion, stillbirth or a previous caesarean, she will be more likely to have the same problem in the subsequent pregnancies. Many study in the world showed a statistically significant association between the disease during pregnancy and pregnancy status. According to the study by Jain, S Anand, S and Aherwar, R. 2014 [9].

\section{Conclusion}

Pregnancy risk occurs when a pregnant woman has a disease or condition sociobiological like high blood pressure, diabetes, alcoholism, obesity, etc., which affects the evolution of pregnancy that can lead to death maternal and/or perinatal. The cross-sectional descriptive study conducted in the city of Lubumbashi 
showed that the prevalence of high-risk pregnancy was $33.1 \%$. The high parity, multiparity, high multigestity, age greater than 35 years were significantly associated with a risk pregnancy. The risk factors of the most common pregnancy in our study were the top 4 parity, bleeding in the third quarter, HTA during the current pregnancy, history of abortion, perinatal death of history, in the lower age to 18 years and above 35 years. At this level, in terms of priorities, we must not forget that the most efficient measure to reduce this risk is not as much as the advancement of prenatal care with known limitations goal, but much more than that of midwifery, is to say at the time of childbirth but also to emphasize the need to better equip maternity draining the highest proportion of women at risk. But for health policy makers and in terms of priorities, we must not forget that the most efficient measure to reduce this risk is not as much as the promotion of prenatal care with known limitations, but that much more than care obstetric, that is to say at the time of delivery and the various levels of care.

\section{References}

[1] Krishna, U., Tank, D.K. and Daftary, S. (2001) Pregnancy at Risk Current Concepts. 4th Edition, Jaypee Brothers (P) Ltd, New Delhi.

[2] Mufti, S. and Mufti, S. (2008) Identification of High Risk Pregnancy by a Scoring System and Its Correlation with Perinatal Outcome. Indian Journal for the Practicing Doctor, 5, 1-7.

[3] Hafez, S.K., Dorgham, L.S. and Suheir Sayed, A.M. (2014) Profile of High Risk Pregnancy among Women in Saudi Taif-KSA. World Journal of Medical Sciences, 11, 90-97.

[4] Jain, S. and Anand, S. and Aherwar, R. (2014) High Risk Scoring for Prediction of Pregnancy Outcome: A Prospective Study. International Journal of Reproduction Contraception, Obstetrics and Gynecology, 3, 516-522. https://doi.org/10.5455/2320-1770.ijrcog20140910

[5] Ferrer, R.L., Sibai, B.M., Murlow, C.D., Chiquette, E., Stevens, K.R. and Cornell, J. (2000) Management of Mild Chronic Hypertension during Pregnancy: A Review. Obstetrics \& Gynecology, 96, 849.

[6] Simarpreet, Mamta, Pooja, et al. (2015) A Study Is High Prevalence of Risk Factors of Pregnancy. Obstetrics and Gynecology, 5, 430-436.

[7] Yassein, S.A., El-Deen, A., Emam, M.A. and Omer, A.K. (2005) The Profile of High-Risk Pregnancy in El-Mansoura City. Journal of the Egyptian Public Health Association, 80, 687-706.

[8] Bharti, Kumar, V., Kaur, A. and Chawla, S. (2016) Prevalence and Correlates of High Risk Pregnancy in Rural Haryana A. International Journal of Basic and Applied Medical Sciences, 3, 212-217.

[9] Jain, S., Anand, S. and Aherwar, R. (2014) High Risk Scoring for Prediction of Pregnancy Outcome: A Prospective Study. International Journal of Contraception Reproduction, Obstetrics and Gynecology, 3, 516-522. https://doi.org/10.5455/2320-1770.ijrcog20140910

[10] Hasan, T. and Al-Khafaji, et al. (2015) Prevalence of Pregnant Women with Multiple Risk Factors Attending Primary Health Center in Erbil. International Journal 
of Humanities and Social Sciences Education (IJHSSE), 2, 104-113.

[11] Akhtar, H., Sultana, S. and Siddique, A. (2009) Come in out Neonatal High Risk Pregnancy. The Journal of Teachers Association, 22, 26-29. 